Research Article

\title{
Cure Kinetics of an Optical Polythiourethane with Amine Catalyst by IR Analysis
}

\author{
Weiping Du $\mathbb{D}^{1},{ }^{1}$ Guiming Zhang, ${ }^{1}$ Song Wang, ${ }^{1}$ Lianjiang Tan, ${ }^{2}$ and Huifang Chen ${ }^{1}$ \\ ${ }^{1}$ State Key Laboratory for Modification of Chemical Fibers and Polymer Materials, College of Materials Science and Engineering, \\ Donghua University, Shanghai 201620, China \\ ${ }^{2}$ Research Institute of Zhejiang University-Taizhou, Taizhou 318000, China
}

Correspondence should be addressed to Weiping Du; duweiping@dhu.edu.cn

Received 25 March 2019; Revised 5 June 2019; Accepted 28 June 2019; Published 16 September 2019

Academic Editor: Atsushi Sudo

Copyright (c) 2019 Weiping Du et al. This is an open access article distributed under the Creative Commons Attribution License, which permits unrestricted use, distribution, and reproduction in any medium, provided the original work is properly cited.

An optical polythiourethane based on m-xylylene diisocyanate (XDI) and 4-mercaptomethyl-3,6-dithia-1,8-octanedithiol (BES) has been studied. Triethylamine was adopted as a catalyst, and the solid-state isothermal cure reaction was carried out using FTIR spectroscopy, in the temperature range of $75^{\circ} \mathrm{C}-105^{\circ} \mathrm{C}$. The $-\mathrm{NCO}$ absorption band of XDI was used to monitor the conversion of diisocyanate into polythiourethane. The reaction rate enhanced with an increase in the content of the catalyst, and the gel time determined by swelling test was shorter for the system with higher catalyst content. Kinetic parameters were calculated from the infrared spectrum data, and the results showed that the curing reaction of polythiourethane accords with first-order kinetic characteristics. The activation parameters obtained from the evaluation of kinetic data were $\triangle H^{*}=97.22 \mathrm{~kJ}$ $\mathrm{mol}^{-1}, \triangle S^{*}=-6.77 \mathrm{~J} \mathrm{~K}^{-1} \mathrm{~mol}^{-1}$, and $E_{\mathrm{a}}=100.23 \mathrm{~kJ} \mathrm{~mol}^{-1}$. The observed negative entropy of activation value supported the formation of a transition state in the cure reaction.

\section{Introduction}

It is generally known that polyurethanes have increasingly attracted attention because of their outstanding properties and wide applications in foams, plastics, rubber, and coatings [1-3]. As a member of the polyurethane family, polythiourethanes (PSU) are formed by a reaction of isocyanates or isothiocyanate with polyols, polythiols, water, and amines containing an active hydrogen atom $[4,5]$. The sulfur element can be from either of the reactants or two of them. The refractive index of polythiourethanes can be as high as 1.71 or even higher due to the addition of the sulfur element in the polyurethane structure [6-9]. Polythiourethanes with high refractive index and low chromatic dispersion have replaced traditional eyeglass lenses and are popular among people, due to their lightness, good impact strength, and good processability [10-14].

The curing of optical polythiourethane involves the formation of a crosslinking network from multifunctional isocyanates and thiols, in which at least one of them is trifunctional or more [15]. The thiourethane linkage
(-NHCOS-) is a result of the reaction between an isocyanate group (-NCO) of isocyanate and a thiol group (-SH) of polythiol. During the three-dimensional crosslinked network forming, the viscosity increased rapidly and molecular weight reached infinity.

The curing reaction of the polyurethane system plays an important role in the manufacturing process as well as the properties of final products [16-18]. The kinetic reaction and mechanism of the cure reaction determine the physicochemical properties and mechanical performance of the cured product [19-21]. Several factors are involved in the formation of urethanes, such as chemical structure and concentration of reagents, reaction medium, and catalyst. Some reports have been published to describe the polymerization kinetics of thermoset polymers $[22,23]$.

A large number of characterization methods have been used to monitor the kinetics of polymerization reactions, such as titration methods, ultrasonic waves, microcalorimetry, differential scanning calorimetry (DSC), Fourier-transform infrared spectroscopy (FTIR), and nuclear magnetic resonance (NMR) measurements [24-29]. FTIR is known as a 


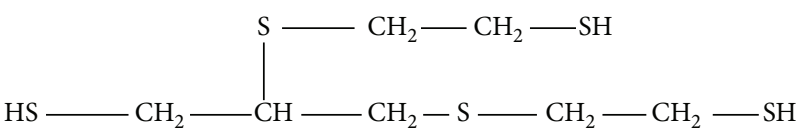

BES

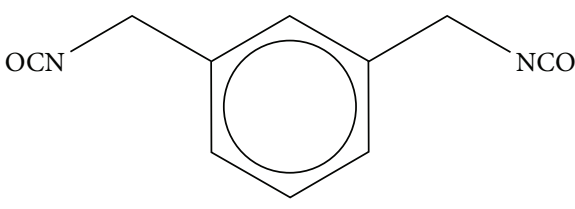

XDI

FIGURE 1: Chemical structure of BES and XDI.

very rapid and reliable method well suited for monitoring the curing process of the PU formation [24, 30].

As far as we know, there have been few studies concerning the kinetics of the optical polythiourethane thermoset process $[21,30]$. In this study, the cure kinetics of the polythiourethane formation between m-xylylene diisocyanate (XDI) and 4-mercaptomethyl-3,6-dithia-1,8-octanedithiol (BES) were researched by using the quantitative FTIR spectroscopy. As one of the important raw materials for commercial high refractive index PSU materials, the kinetics of XDI participating in the curing reaction of polythiourethane have not been studied. Triethylamine (TEA) was used as the catalyst to speed up the polythiourethane formation, and the effect of the catalyst concentration on the reaction kinetics was also investigated. Kinetic and thermodynamic parameters were calculated using normalized conversion curves. The results will provide references for the curing process of optical polythiourethane, such as PSU coatings, films, or lens productions.

\section{Materials and Methods}

2.1. Materials. 4-mercaptomethyl-3,6-dithia-1,8-octanedithiol (BES, 99\%) and m-xylylene diisocyanate (XDI, 98\%) were provided by Mitsui Chemicals. The chemical structures are shown in Figure 1. The phosphate mold release agent was provided by Shanghai Longxu Chemicals. Triethylamine (TEA, 99\%) and dimethylformamide (DMF, 99\%) were purchased from Aladdin. All the chemicals were used without further purification.

2.2. Crosslinking of Polythiourethane. The PSU thermoset system was prepared from the reaction of BES and XDI. The two reactants for crosslinking were mixed in a molar ratio of $1: 1$. Two drops of phosphate mold release agent and proper TEA were mixed under stirring for $10 \mathrm{~min}$ and degassed under vacuum for $20 \mathrm{~min}$. All operations were carried out in a glove box at $5^{\circ} \mathrm{C}$ and $\mathrm{N}_{2}$ gas protection to avoid the reaction between $\mathrm{H}_{2} \mathrm{O}$ and XDI. The polythiourethane reaction system was prepared freshly for FTIR measurements.

2.3. FTIR Spectroscopy Measurements. A Nicolet 6700 FTIR spectrophotometer using the OMNIC program was used to monitor the curing process of optical polythiourethane, within a range of $400-4000 \mathrm{~cm}^{-1}$ at a resolution of $4 \mathrm{~cm}^{-1}$. The absorbance spectra were recorded at proper time intervals, measuring the progressive decrease of the NCO band at $2260 \mathrm{~cm}^{-1}$. The temperature of the sample oven was controlled by a thermoregulator. Isothermal polymerization kinetic parameters were evaluated at $75^{\circ} \mathrm{C}, 90^{\circ} \mathrm{C}$, and $105^{\circ} \mathrm{C}$, respectively. $\mathrm{CH}_{2}$ stretching at $2920 \mathrm{~cm}^{-1}$ was chosen as an internal standard because it remained practically unaffected throughout the curing reaction. The normalized data were used to calculate the kinetic and thermodynamic parameters for the cure reaction.

2.4. Thermodynamic Parameters. Thermodynamic parameters were determined using the Arrhenius law (Equation (1)), and the Eyring relationship (Equation (2)) was used to determine the activation enthalpy $\left(\Delta H^{*}\right)$ and entropy $\left(\Delta S^{*}\right)$,

$$
\begin{aligned}
k & =A e^{-E_{\mathrm{a}} / R T}, \\
\ln \frac{k}{T} & =\ln \frac{R}{N h}+\frac{\Delta S^{*}}{R}-\frac{\Delta H^{*}}{R T},
\end{aligned}
$$

where $k$ is the kinetic constant, $A$ is the frequency factor, $E_{\mathrm{a}}$ is the activation energy, $R$ is the universal gas constant, $T$ is the temperature, $N$ is Avogadro's constant, and $h$ is Planck's constant.

2.5. Swelling Measurements. The gel time was measured using a solubility method, where the time when the insoluble polymer first appears in the dimethylformamide (DMF) solvent was measured at room temperature. Under the isothermal conditions, several unreacted samples (W1) were placed in the oven. After a certain interval, a sample was removed and immersed into the DMF solvent at room temperature for a week until swollen equilibrium was obtained. Then, the solvent was vaporized and the dry sample weighted as W2. The percentage of the insoluble portion of the initial sample gave the gel fraction $(G)$. Measurements were repeated at least for three parallel samples in each case and the results were averaged.

$$
\text { Gel fraction }(G)=\frac{\mathrm{W} 2}{\mathrm{~W} 1} \times 100 \%
$$

\section{Results and Discussion}

3.1. FTIR Analysis. The polythiourethane formation can be depicted in a simple manner, as seen in Figure 2.

Theoretically, nucleophilic reaction could occur between isocyanate and any compound with active hydrogen. Due to the induction effect, the carbon atom and the oxygen atom in the -NCO group form an electrophilic center and a nucleophilic center, respectively. When isocyanates react with thiols, the oxygen atoms in the -NCO group accept the hydrogen atoms in the $-\mathrm{SH}$ group to form carbonyl groups. 


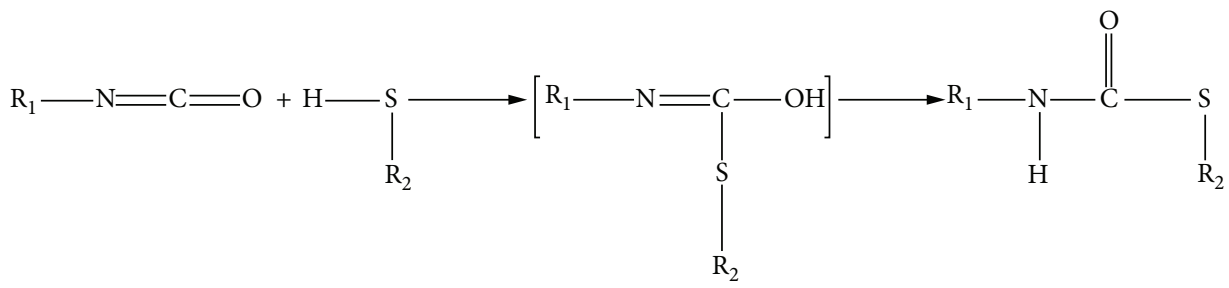

FIGURE 2: A diagram of polythiourethane formation.

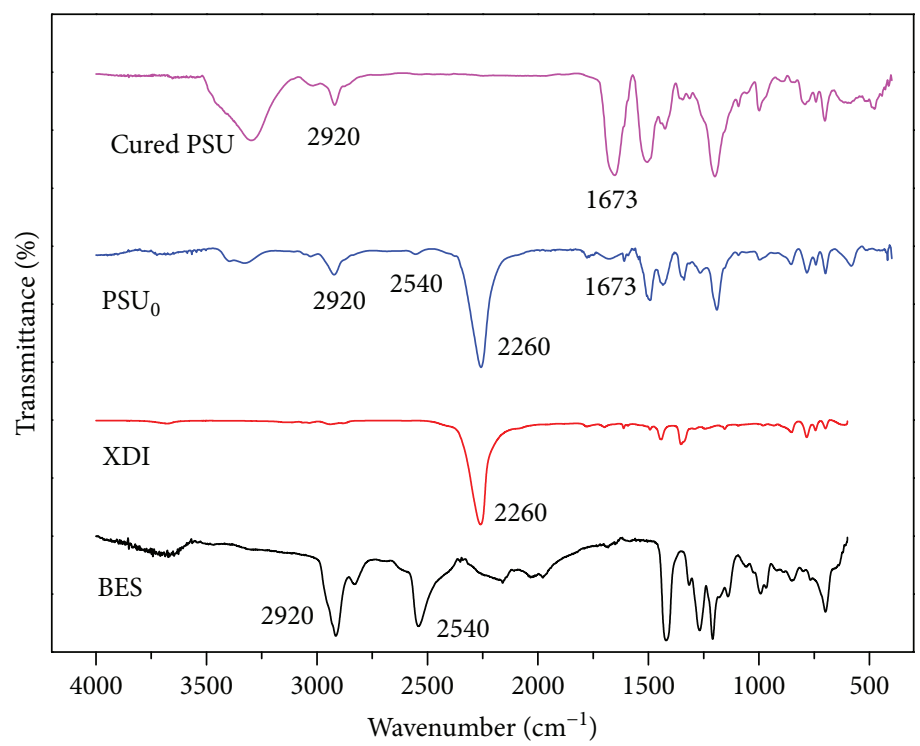

FIgURe 3: FTIR spectra of the BES, XDI, PSU ${ }_{\mathrm{o}}$ and cured PSU.

Because of the instability of hydroxyls on the unsaturated carbon atoms, the structure undergoes intramolecular rearrangement and the - NH-COS- group is formed.

Figure 3 gives the FTIR spectra of the BES, XDI, PSU (mixture of BES and XDI just after preparation), and the cured PSU. The details of the FTIR bands are presented in Table 1. The absorption band for the NCO stretching of XDI is at around $2260 \mathrm{~cm}^{-1}$, which can be used to monitor the isocyanate group conversion during polymerization [28]. On the other hand, the characteristic bands of $\mathrm{C}=\mathrm{O}$ at $1673 \mathrm{~cm}^{-1}$ and $\mathrm{NH}$ at $3510-3100 \mathrm{~cm}^{-1}$ were clearly observed in the spectra of the cured sample, which also proved the formation of polythiourethane [28, 31]. The absorption at $2540 \mathrm{~cm}^{-1}$ is due to $-\mathrm{SH}$ of BES [32].

Quantification is based on the Lambert-Beer law. Assuming that no obvious side reactions occur in the polymerization reaction [15], the decrease of the intensity of the $2260 \mathrm{~cm}^{-1}$ band was used to monitor the conversion of the -NCO group with $-\mathrm{CH}_{2}$ stretch absorbance $\left(2920 \mathrm{~cm}^{-1}\right)$ as the internal standard.

The cure reaction between the BES and XDI can be followed by means of quantitative FTIR spectroscopy. Figure 4 shows the IR spectra taken in the course of the PSU formation between BES and XDI at $105^{\circ} \mathrm{C}$ with $150 \mathrm{ppm}$ TEA in the system. The absorbance peak of the isocyanate at $2260 \mathrm{~cm}^{-1}$ decreased due to the reaction between
TABLe 1: Principal peak assignments in the FTIR spectra of BES, $\mathrm{XDI}, \mathrm{PSU}_{\mathrm{o}}$, and cured PSU.

\begin{tabular}{lc}
\hline Observed peaks $\left(\mathrm{cm}^{-1}\right)$ & Peak assignments \\
\hline $3510-3100$ & $-\mathrm{NH}$ stretching vibrations \\
2920 & $-\mathrm{CH}_{2}$ stretching vibration \\
2540 & $-\mathrm{SH}$ stretching vibration \\
2260 & $-\mathrm{NCO}$ stretching vibration \\
1673 & $-\mathrm{C}=\mathrm{O}$ stretching vibration of $\mathrm{PSU}$ \\
\hline
\end{tabular}

the -SH of BES and the -NCO of XDI. As can be seen, NCO stretching bands at $2260 \mathrm{~cm}^{-1}$ disappeared gradually and the $\mathrm{C}=\mathrm{O}$ stretching band at $1673 \mathrm{~cm}^{-1}$ increased simultaneously, which indicate the conversion of isocyanate to polythiourethane.

3.2. Influence of Temperature on Isocyanate Conversion. Using peak height to represent peak intensity, isocyanate conversion $p$ can be expressed as $[33,34]$

$$
\text { NCO conversion }(p)=1-\frac{A_{t} / A_{I t}}{A_{0} / A_{\mathrm{I} 0}}
$$

where $A_{0}$ and $A_{t}$ correspond to the peak intensity of absorbance $\left(2260 \mathrm{~cm}^{-1}\right)$ at the initial time and specified time 


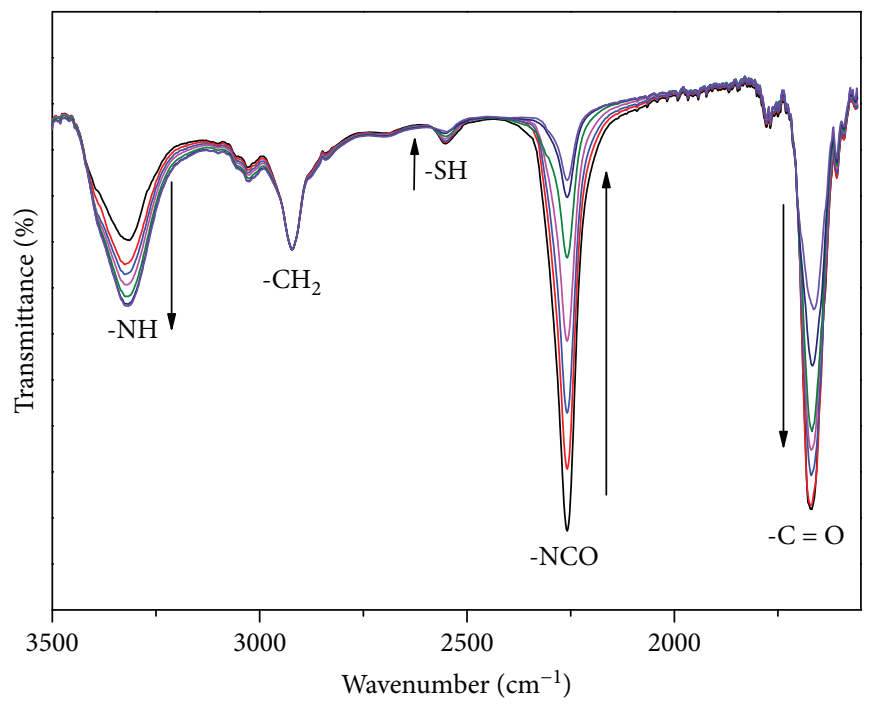

FIgURE 4: FTIR spectra of PSU with $150 \mathrm{ppm}$ TEA at $105^{\circ} \mathrm{C}$ at different curing times. (curing time from bottom to top is $5,7,10,15,20,30$, and $40 \mathrm{~min}$ ).

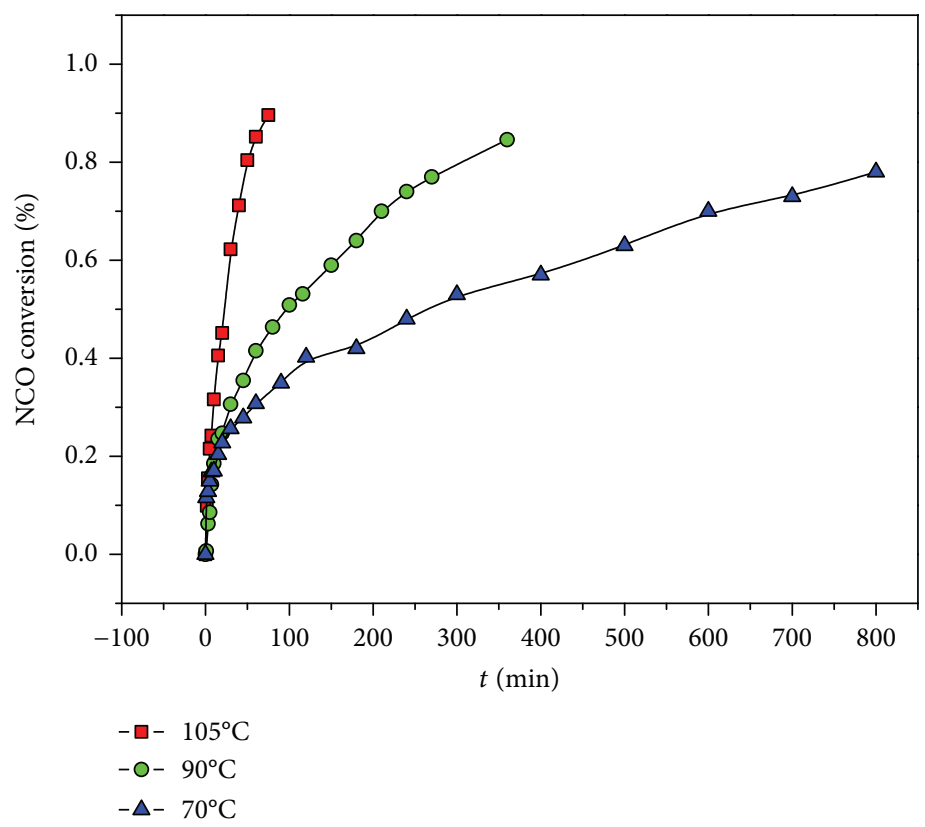

Figure 5: Isocyanate conversion versus curing time of PSU at $75^{\circ} \mathrm{C}, 90^{\circ} \mathrm{C}$, and $105^{\circ} \mathrm{C}$ with $150 \mathrm{ppm}$ TEA.

during the curing, respectively. $A_{I 0}$ and $A_{I t}$ are the peak intensity of absorbance $\left(2920 \mathrm{~cm}^{-1}\right)$ which is assigned to the internal standard. Many papers have used the isocyanate conversion $p$ to research the curing process of thermosetting systems. Pradip et al. [33] have researched the curing of polyurethane prepolymers with three hyperbranched polyols and found that all polyurethane formations in their study followed the second-order kinetics. In our previous work [34], rheological measurements and FTIR spectroscopy were used to investigate the curing of XDI and BES system with dibutyltin dichloride as the catalyst. The isocyanate conversion was calculated and the conversion vs. time was observed.
Figure 5 shows the results of -NCO conversion of XDI with the $-\mathrm{SH}$ group of $\mathrm{BES}$ at $75^{\circ} \mathrm{C}, 90^{\circ} \mathrm{C}$, and $105^{\circ} \mathrm{C}$. Apparently, the conversion increased with time until -NCO was consumed completely. The conversion rate increased with the increase of temperature. At $105^{\circ} \mathrm{C}$, the conversion reached about $90 \%$ within $75 \mathrm{~min}$, while it took $6 \mathrm{~h}$ for the conversion to reach $85 \%$ at $90^{\circ} \mathrm{C}$. For $75^{\circ} \mathrm{C}$, the polymerization occurred more slowly and the - $\mathrm{NCO}$ conversion was only around $80 \%$ even if it has been reacting for $14 \mathrm{~h}$.

3.3. Curing Kinetics. The understanding of the mechanism and kinetics of the curing is very important in the 


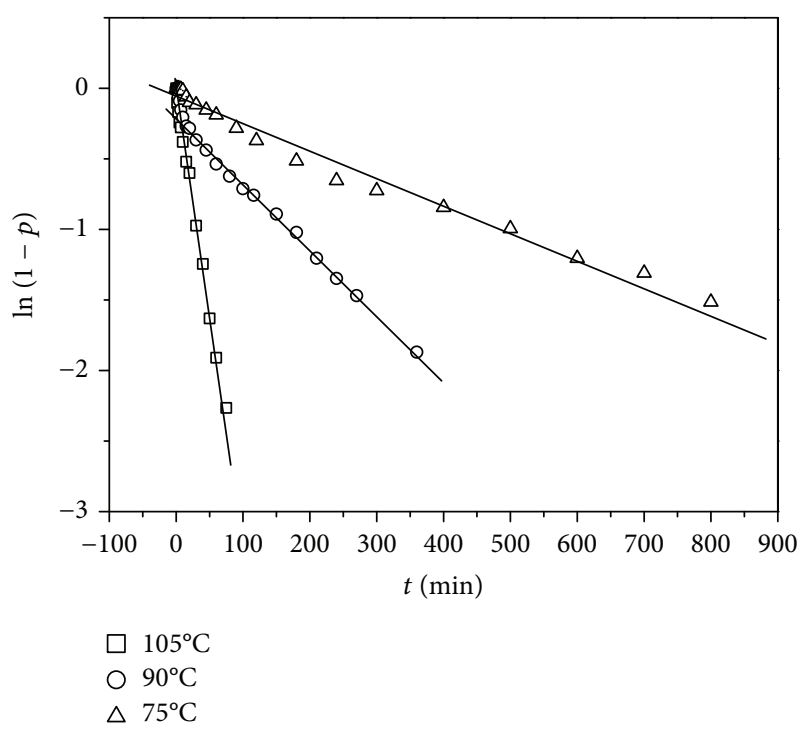

(a)

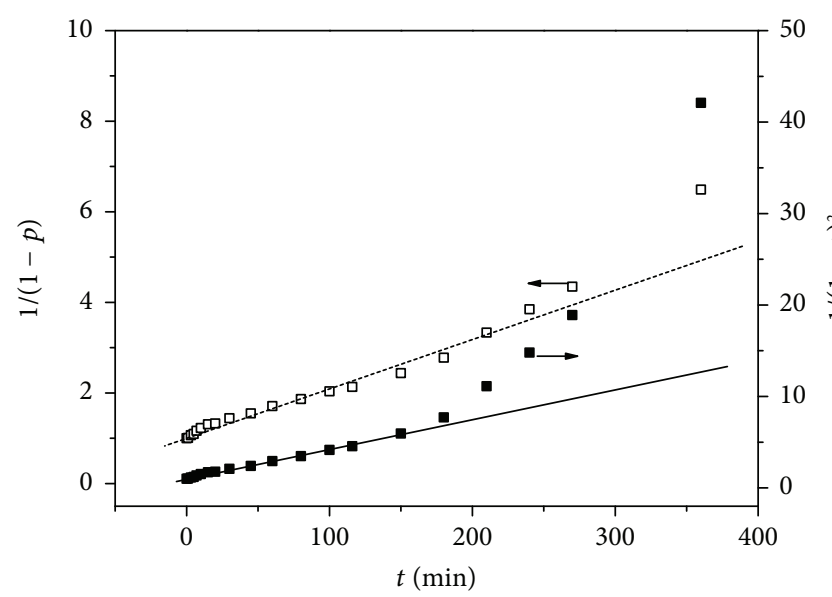

$90^{\circ} \mathrm{C}$

$\square$ 2nd kinetics fitting $\quad$ _ Linear fit
- 3rd kinetics fitting $\quad$ - - Linear fit

(c)

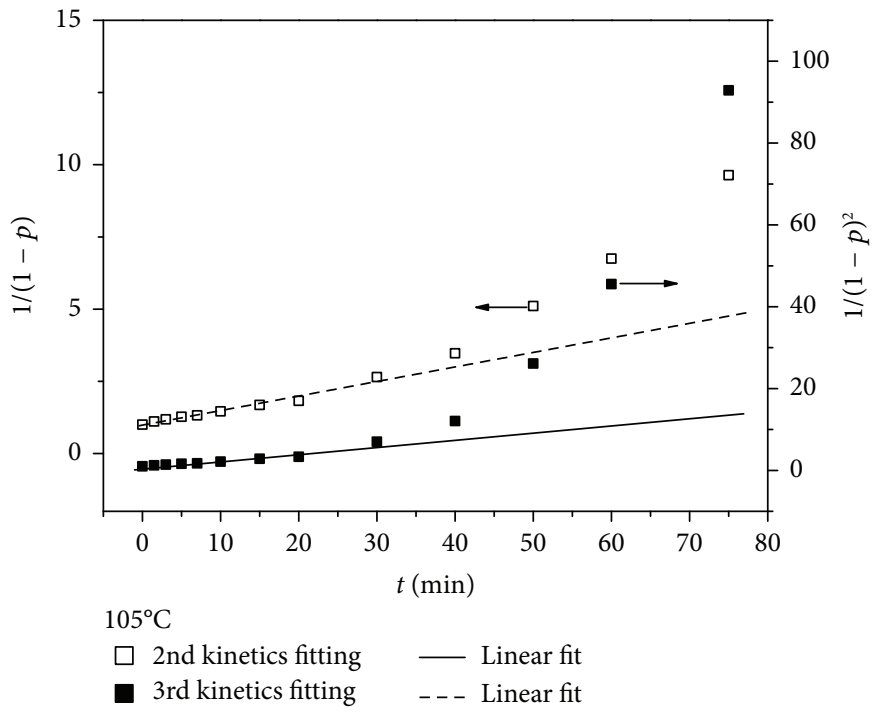

(b)

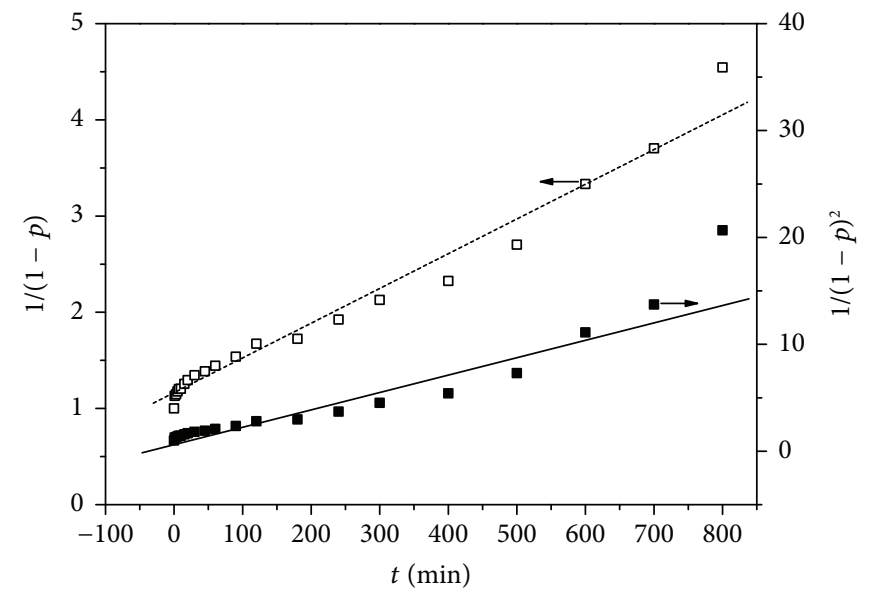

$70^{\circ} \mathrm{C}$

$\square$ 2nd kinetics fitting _ Linear fit

- 3rd kinetics fitting - - - Linear fit

(d)

FIGURE 6: First-order rate law for PSU with 150 ppm TEA at different temperature (a). Second-order rate law and third-order rate law for PSU with $150 \mathrm{ppm}$ TEA at $105^{\circ} \mathrm{C}(\mathrm{b}), 90^{\circ} \mathrm{C}(\mathrm{c})$, and $75^{\circ} \mathrm{C}(\mathrm{d})$.

evaluation of structure-morphology-property relationships of a material. Kinetic mechanisms describing polythiourethane formation between thiols and isocyanates are not well understood. The following rate law was adopted to describe the polymerization reaction:

$$
\frac{\mathrm{d}[\mathrm{NCO}]}{\mathrm{d} t}=-k[\mathrm{NCO}]^{a}[\mathrm{SH}]^{b}
$$

where $k$ is the rate constant and [NCO] and [SH] are the concentrations of isocyanate and thiol, respectively. Similarly, the exponents $a$ and $b$ represent the order of reaction with respect to isocyanate and thiol, respectively. $n=a+b$ is the overall order of reaction.
The empirical schemes, $n$th order, is widely used for modelling the cure kinetics for thermosetting materials $[15,35]$. The $n$ th-order kinetics can be expressed as

$$
\frac{\mathrm{d} p}{\mathrm{~d} t}=k(1-p)^{n}
$$

Here $p$ is the degree of cure (isocyanate conversion), and $k$ is the constants related to the rate constants, which depends on the temperature. The parameter $n$ is related to the reaction order. Here we used the $n$ th-order approach for modelling the curing kinetics of PSU. If the curve $\ln (1-P)$ plotted against time is a straight line, the mechanism of this reaction follows a first order. If the 
TABLE 2: First-order kinetic parameters and thermodynamic parameters of PSU curing process with 150 ppm TEA.

\begin{tabular}{lcccc}
\hline Temperature $(\mathrm{K})$ & \multicolumn{2}{c}{$\begin{array}{c}\text { 1st-order equation } \\
\text { ( }\left(\mathrm{min}^{-1}\right)\end{array}$} & $R^{2}$ & $\Delta H^{*}\left(\mathrm{~kJ} \mathrm{~mol}^{-1}\right)$ \\
\hline 348 & 0.0019 & 0.988 & & $\Delta S^{*}\left(\mathrm{~J} \mathrm{~mol} \mathrm{~mol}^{-1}\right)$ \\
363 & 0.0051 & 0.981 & 100.23 & 97.22 \\
378 & 0.0301 & 0.997 & & -20.13 \\
\hline
\end{tabular}

$$
\mathrm{N}\left(\mathrm{CH}_{2} \mathrm{CH}_{3}\right)_{3}+\mathrm{R}_{2}-\mathrm{SH} \rightleftharpoons \mathrm{N}\left(\mathrm{CH}_{2} \mathrm{CH}_{3}\right)_{3} \mathrm{H}^{+}+\mathrm{R}_{2}-\mathrm{S}^{-}
$$

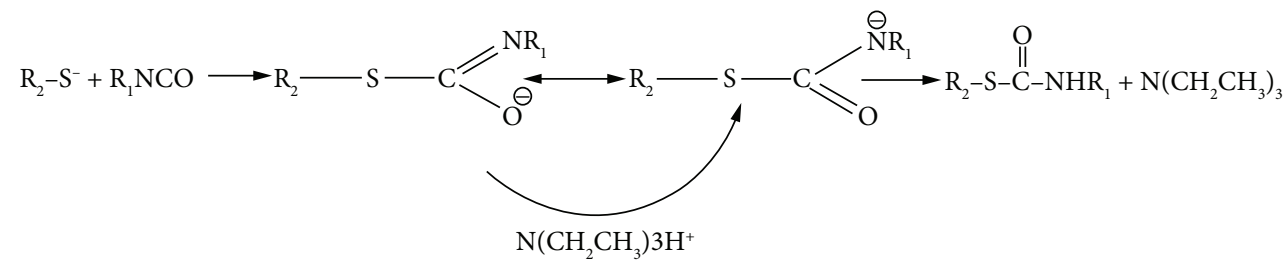

FIgURE 7: Mechanism of nucleophilic addition between isocyanate and thiol catalyzed by TEA.

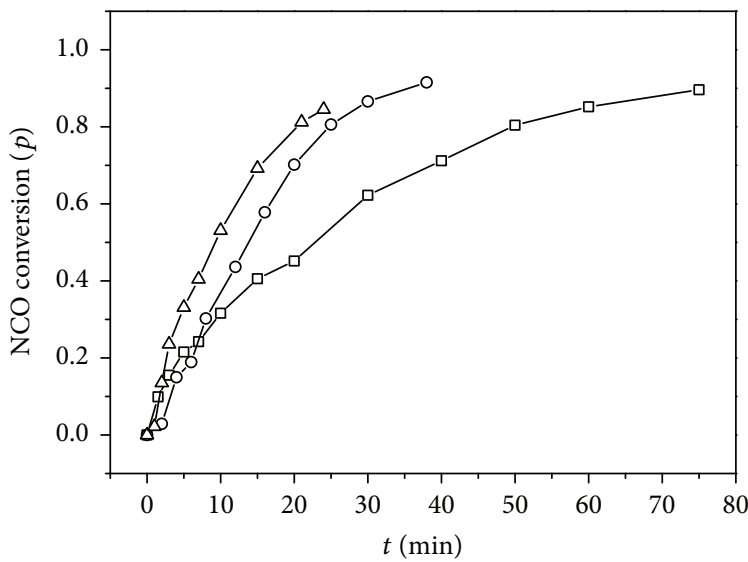

TEA

- - $100 \mathrm{ppm}$

- $-150 \mathrm{ppm}$

$-\Delta-200 \mathrm{ppm}$

(a)

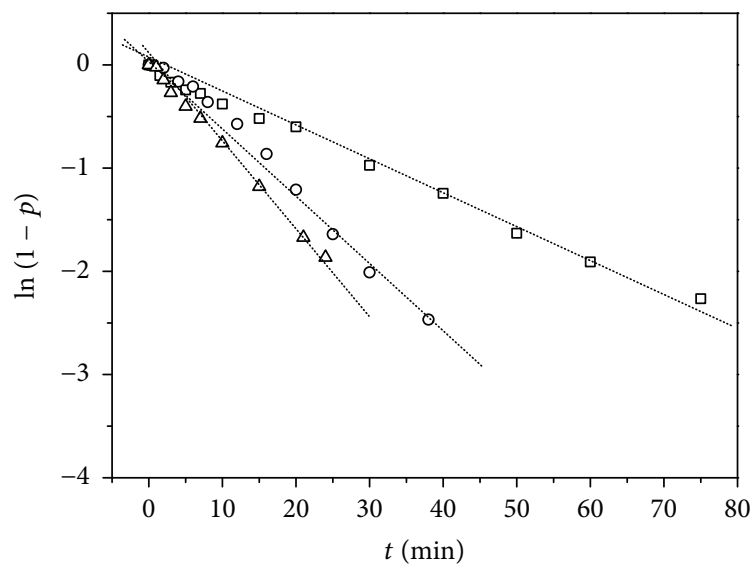

$\square 100 \mathrm{ppm} \quad \triangle 200 \mathrm{ppm}$

(b)

FIGURE 8: Isocyanate conversion versus curing time of PSU with different TEA content at $105^{\circ} \mathrm{C}(\mathrm{a})$ and the corresponding first-order rate law.

curve $(1 /(1-p))$ plotted against time is a straight line, the mechanism of this reaction follows a second order. And so on.

If $n=1, \ln (1-p)=-k t+C$.

If $n=2,1 /(1-p)=k t+C$.

If $n=3,1 /(1-p)^{2}=k t+C$, where $C$ is the integration constant.

The polythiourethane formation between BES and XDI with $150 \mathrm{ppm}$ TEA was conducted at three different temperatures in the range of $75-105^{\circ} \mathrm{C}$ to determine the kinetics parameters of the reaction. The curves to which the three equations are applied for the PSU are shown in Figure 6. Comparing the results, it is evident that PSU polymerization is a typical first-order reaction, because only the plots of $\ln$
TABLE 3: First-order kinetic parameters of PSU curing process at $105^{\circ} \mathrm{C}$ with different TEA content.

\begin{tabular}{lccc}
\hline \multirow{2}{*}{ Temperature $(\mathrm{K})$} & Catalyst content $(\mathrm{ppm})$ & \multicolumn{2}{c}{1 st-order equation } \\
& $K\left(\mathrm{~min}^{-1}\right)$ & $R^{2}$ \\
\hline 378 & 100 & 0.0301 & 0.997 \\
378 & 150 & 0.0688 & 0.991 \\
378 & 200 & 0.0790 & 0.998 \\
\hline
\end{tabular}

$(1-p)$ versus time were found to be linear (Figure 6(a)). The rate constants $k$ from the slope of the linear fit line are listed in Table 2 for different curing temperatures. From the experimental results, it can be seen that the curing reaction rate constant rises notably at higher temperature, which 


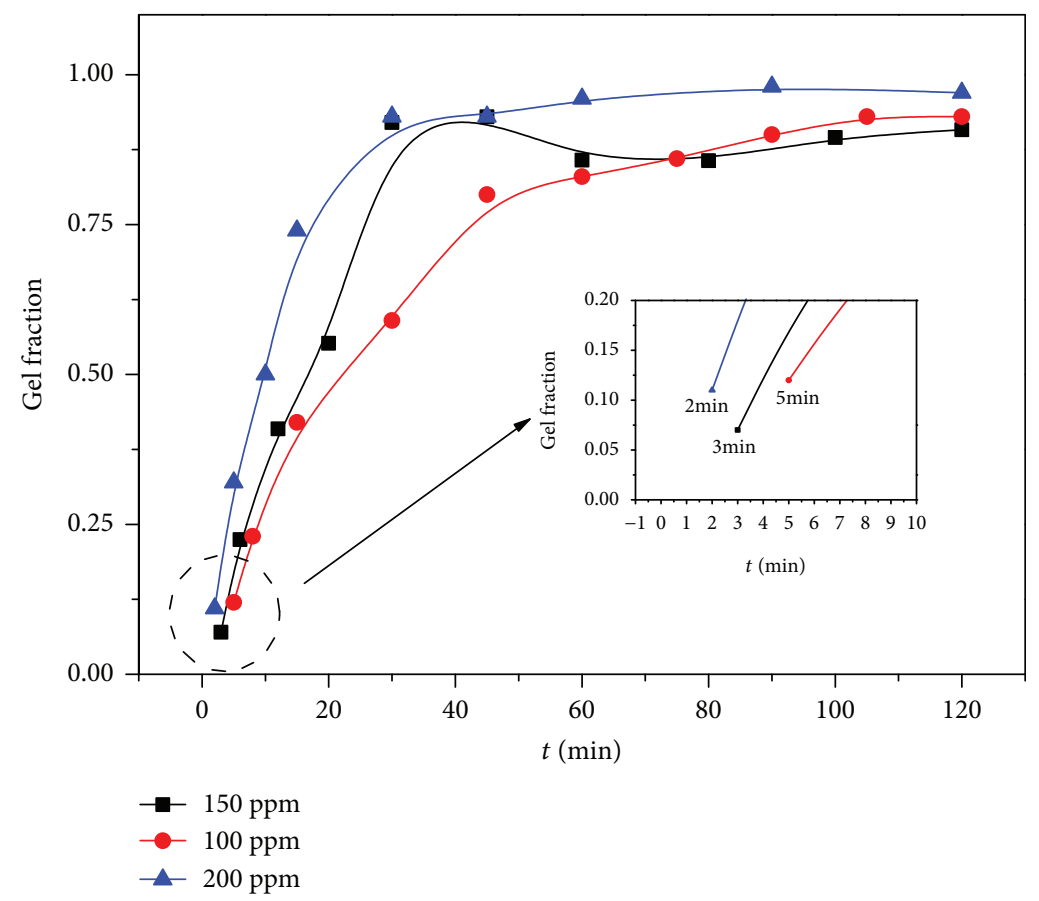

Figure 9: Gel time with different TEA content at $105^{\circ} \mathrm{C}$.

means the polymerization reaction between BES and XDI is accelerated with the increase of temperature.

3.4. Influence of the Catalyst on the Cure Reaction Rate. The amine catalysts are known to be the most suitable catalysts for the urethane formation [36, 37]. Triethylamine (TEA) was selected in this work to be used as a catalyst for the polythiourethane formation between - $\mathrm{SH}$ and -NCO. The reaction mechanism of nucleophilic addition between thiol and NCO catalyzed by TEA is shown in Figure 7. First, an anionic thiol is formed by TEA, and then the anionic thiol is attacked by isocyanate to form a complex. Finally, the proton is transferred to the complex and the NHCOS is obtained [36].

Active catalysts allow a rapid reaction of the PSU system. The polythiourethane formation between BES and XDI was carried out in the presence of a catalyst with different concentrations at $105^{\circ} \mathrm{C}$, as shown in Figure 8, and the first-order kinetic parameters are listed in Table 3. During the curing reactions of PSU, a three-dimensional crosslinking network is formed and -NCO groups are consumed gradually. The conversion rate of -NCO is larger with a higher catalyst concentration. -NCO groups converted 92\% taking 28 minutes with a $200 \mathrm{ppm}$ catalyst, while taking 38 minutes with a 150 ppm catalyst. When the catalyst concentration is as low as $100 \mathrm{ppm}$, it spent over $75 \mathrm{~min}$ for the -NCO conversion to $90 \%$.

When a crosslinked polymer is immersed in an appropriate solvent, the polymer imbibes the solvent and undergoes swelling. When the insoluble polymer first appears, the gel and the crosslinked network form. Gelation times with different catalyst contents were determined through swelling measurement and are shown in Figure 9. No gel was formed at the beginning, but after an induc- tion period, a gel was formed and the gel fraction increased very quickly as the cure proceeded. Obviously, the gel with a high catalyst content appeared earlier, indicating a faster reaction. This is consistent with the conclusion we mentioned above.

Although it seems to be applicable, the $n$ th-order approach has some limits as the reaction process is very complex. In a polymerization process, the liquid reactants slowly become solid as the reaction proceeds, and obviously, the reaction mechanisms are changing. Many reports have shown that the curing reaction is controlled by the diffusion in the last part of the reaction $[38,39]$. Even so, this approach has proved to be able to reflect the process to a great extent.

3.5. Calculation of the Activation Energy, Activation Enthalpy, and Entropy. Activation energy of the PSU formation was determined according to equation (1), as listed in Table 2. $E_{\mathrm{a}}$ is $100.23 \mathrm{~kJ} \mathrm{~mol}^{-1}$, a comparatively large value, indicating that the curing reaction of PSU must have occurred in the presence of a catalyst and/or heating to some extent.

Activation enthalpy $\left(\Delta H^{*}\right)$ and entropy $\left(\Delta S^{*}\right)$ gained from the Eyring relationship are very useful to understand the reaction mechanism. The Eyring relationship (equation (2)) was used to determine the values and $\Delta H^{*}$ and $\Delta S^{*}$ are presented in Figure 9 and Table 2.

The Eyring plot for the thermal curing reaction between BES and XDI is illustrated in Figure 10, which gives a straight line. In curing processes, thermodynamic parameter values are the actual indicators for practical applications. The activation enthalpies and entropies can be obtained from the evaluation of the Eyring plot. The activation enthalpy was found to be $\Delta H^{*}=97.22 \mathrm{~kJ} \mathrm{~mol}^{-1}$ and the activation entropy can be found to be $\Delta S^{*}=-20.13 \mathrm{~J} \mathrm{~K}^{-1} \mathrm{~mol}^{-1}$. 

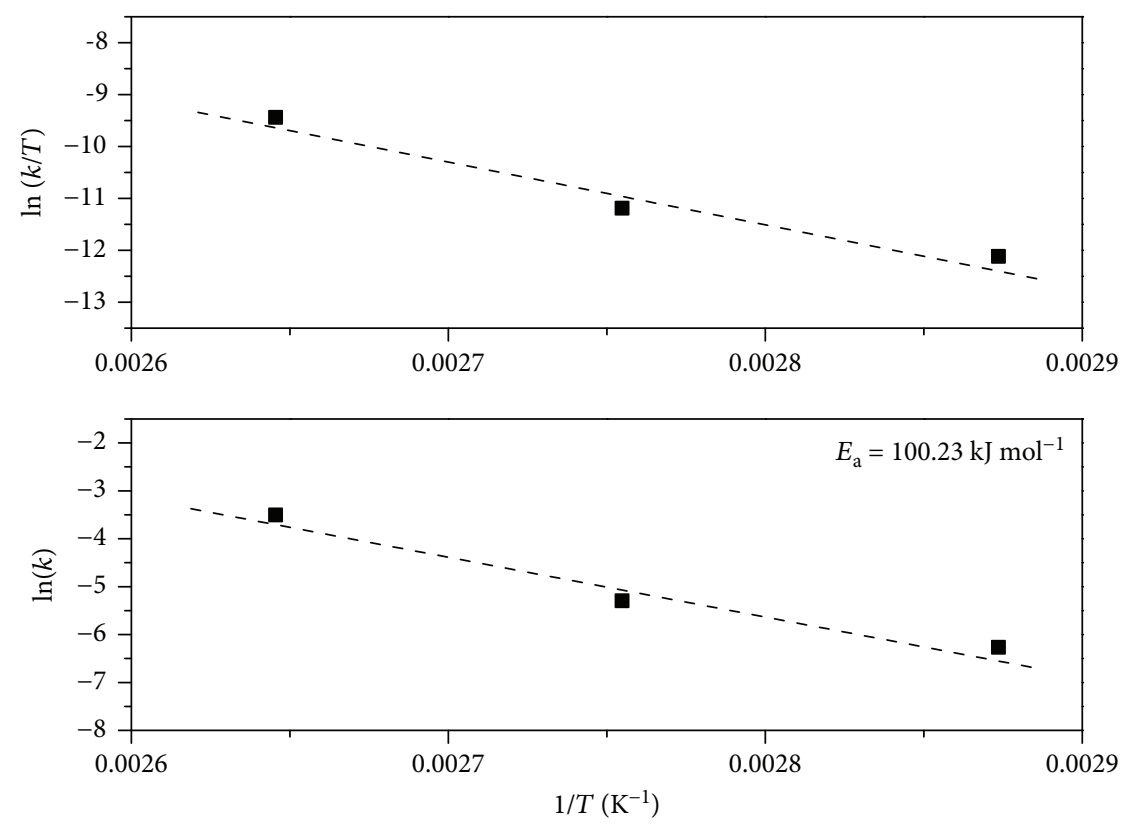

$\Delta \mathrm{H}^{*}=97.22 \mathrm{~kJ} \mathrm{~mol}^{-1}$
$\Delta \mathrm{S}^{*}=-20.13 \mathrm{~J} \mathrm{~mol}^{-1}$

Figure 10: $\ln (k)$ and $\ln (\mathrm{k} / T)$ versus reciprocal of curing temperature of PSU.

As shown in Table 2, the positive $\Delta H^{*}$ value indicates that the curing process is endothermic in nature. This is consistent with the above results where the isocyanate conversion increased with the increasing temperature. In addition, high values for the activation enthalpies were found, indicating that strong associations between the hydroxyl groups were present for polyurethane systems [40]. These could be considered similar to those present in thiol groups in BES-XDI systems, according to $\Delta H^{*}$ values (Table 2). The value for the activation entropy was negative, which attested to an associative mechanism in the transition state [40]. Support for this assignment of an associated mechanism in the transition states for the polythiourethane formation between BES and XDI comes from comparison of the activation enthalpies with the bond energies of the $\mathrm{S}-\mathrm{H}$ and $\mathrm{C}=\mathrm{N}$ bonds $(363 \mathrm{~kJ} / \mathrm{mol}$ for $\mathrm{S}-\mathrm{H}$ and $615 \mathrm{~kJ} / \mathrm{mol}$ for $\mathrm{C}=\mathrm{N}$ ), which were broken in the reaction. The activation enthalpy was much smaller than the bond energy.

\section{Conclusions}

The kinetic studies on the optical polythiourethane formation have been performed by means of quantitative FTIR spectroscopy. m-Xylylene diisocyanate (XDI) and 4-mercaptomethyl3,6-dithia-1,8-octanedithiol (BES) were used as the key raw materials. The curing reaction of the optical polythiourethane exhibits first-order kinetics. Triethylamine added as a catalyst can significantly accelerate the reaction process, probably due to the formation of the intermediate transition state. The negative value of the activation entropy, as well as the comparison between the activation enthalpy and the dissociation energies of the breaking bonds, confirms that transition states may be formed during the curing process.

\section{Data Availability}

The data used to support the findings of this study are available from the corresponding author upon request.

\section{Conflicts of Interest}

The authors declare that there is no conflict of interest regarding the publication of this paper.

\section{Acknowledgments}

This work was financially supported by the National Key Research and Development Program of China (2016YFB0302300) and the Taizhou Science and Technology Project (1017GY15).

\section{References}

[1] B. Florczak, "Viscosity testing of HTPB rubber based prebinders," Central European Journal of Energetic Materials, vol. 11, pp. 625-637, 2014.

[2] H. Sheikhy, M. Shahidzadeh, B. Ramezanzadeh, and F. Noroozi, "Studying the effects of chain extenders chemical structures on the adhesion and mechanical properties of a polyurethane adhesive," Journal of Industrial and Engineering Chemistry, vol. 19, no. 6, pp. 1949-1955, 2013.

[3] W. Xia, N. Zhu, R. Hou, W. Zhong, and M. Chen, "Preparation and characterization of fluorinated hydrophobic UV-crosslinkable thiol-ene polyurethane coatings," Coatings, vol. 7, no. 8, pp. 117-129, 2017. 
[4] Z. Yang, Y.-n. Lin, Z. Zhu, and B. G. Risch, Optical Terpolymer of Polyisocyanate, Polythiol and Polyene Monomers, Optima, Inc., 1995.

[5] G. Sotgiu, M. Zambianchi, G. Barbarella, F. Aruffo, F. Cipriani, and A. Ventola, "Rigid-core fluorescent oligothiophene-s,sdioxide isothiocyanates. Synthesis, optical characterization, and conjugation to monoclonal antibodies," Journal of Organic Chemistry, vol. 68, no. 4, pp. 1512-1520, 2003.

[6] E. Marianucci, C. Berti, F. Pilati, P. Manaresi, M. Guaita, and O. Chiantore, "Refractive index of poly(thiocarbonate)s and poly(dithiocarbonate)s," Polymer, vol. 35, no. 7, pp. 1564-1566, 1994.

[7] T. Higashihara and M. Ueda, "Recent progress in high refractive index polymers," Macromolecules, vol. 48, no. 7, pp. 1915-1929, 2015.

[8] T. Okubo, S. Kohmoto, and M. Yamamoto, "Preparation, characterization, and optical properties of disulfidecomprising oligo[2,5-bis(thiomethyl)-1,4-dithiane] and its poly[S-alkylcarbamate]," Journal of Materials Science, vol. 34, no. 2, pp. 337-347, 1999.

[9] N. D. Ghatge and R. Murthy, "Polythiourethane polymers using castor oil tristhioglycolate as crosslinking agent," Journal of Applied Polymer Science, vol. 27, no. 5, pp. 1557-1563, 1982.

[10] H. Morishiri and S. Kobayashi, "Polythiol for highly heat resistant resin," JP Patent 2006131724, 2006.

[11] R. Okada, T. Ohkubo, and M. Kosaka, "Polymer for optical products and process for preparation thereof," CA Patent 19922077150, 1993.

[12] J. Shin, J. Shim, S. M. Kim, and H. M. Seo, "New polythiol compound used in polymerizable composition for forming polythiourethane-based compound used for optical material e.g. plastic optical lens, includes thiol groups," US Patent WO2017095119-A1, 2017.

[13] S. M. Hong, J. H. Myung, H. M. Seo et al., "Polymerizable composition used for producing polythiourethane compound for forming optical material, comprises polythiol compound, isocyanate compound and mono- to tetravalent carboxylic acid and/or phosphoric acid," US Patent WO2018004217-A2, 2018.

[14] S. Hong, Z. Ming, J. Shin, S. M. Hong, and J. H. Myung, "Polymerizable composition for plastic lens, comprises isocyanate compound having two or more functional groups, thiol compound having two or more functional groups having one sulfur bond or one ester bond, and catalyst," US Patent CN108276555-A, 2018.

[15] Q. Li, H. Zhou, D. A. Wicks, C. E. Hoyle, D. H. Magers, and H. R. McAlexander, "Comparison of small molecule and polymeric urethanes, thiourethanes, and dithiourethanes: hydrogen bonding and thermal, physical, and mechanical properties," Macromolecules, vol. 42, no. 6, pp. 1824-1833, 2009.

[16] N. Droger, O. Primel, and J. L. Halary, "Characterization of the viscoelastic and mechanical properties of tightly cross-linked polythiourethane networks," Journal of Applied Polymer Science, vol. 107, no. 1, pp. 455-462, 2008.

[17] H. Ma, Y. C. Liu, T. Chai et al., "Kinetic studies on the cure reaction of hydroxyl-terminated polybutadiene based polyurethane with variable catalysts by differential scanning calorimetry," e-Polymers, vol. 17, no. 1, pp. 89-94, 2017.

[18] B. Lucio and J. L. de la Fuente, "Rheokinetic analysis on the formation of metallo-polyurethanes based on hydroxyl- terminated polybutadiene," European Polymer Journal, vol. 50, pp. 117-126, 2014.

[19] A. Kultys, M. Rogulska, and S. Pikus, "The synthesis and characterization of new thermoplastic poly(thiourethaneurethane)s," Journal of Polymer Science Part A: Polymer Chemistry, vol. 46, no. 5, pp. 1770-1782, 2008.

[20] S. Lee, J. H. Choi, I.-K. Hong, and J. W. Lee, "Curing behavior of polyurethane as a binder for polymer-bonded explosives," Journal of Industrial and Engineering Chemistry, vol. 21, pp. 980-985, 2015.

[21] B. Jaffrennou, N. Droger, F. Mechin, J. L. Halary, and J. P. Pascault, "Characterization, structural transitions and properties of a tightly crosslinked polythiourethane network for optical applications," e-Polymers, vol. 5, no. 1, p. 82, 2005.

[22] C. Garschke, P. P. Parlevliet, C. Weimer, and B. L. Fox, "Cure kinetics and viscosity modelling of a high-performance epoxy resin film," Polymer Testing, vol. 32, no. 1, pp. 150-157, 2013.

[23] R. Geissberger, J. Maldonado, N. Bahamonde, A. Keller, C. Dransfeld, and K. Masania, "Rheological modelling of thermoset composite processing," Composites Part B: Engineering, vol. 124, pp. 182-189, 2017.

[24] J. Shin, J. Lee, and H. M. Jeong, "Properties of polythiourethanes prepared by thiol-isocyanate click reaction," Journal of Applied Polymer Science, vol. 135, no. 14, article 46070, 2018.

[25] J. Han, C. Yu, Y. Lin, and K. Hsieh, "Kinetic study of the urethane and urea reactions of isophorone diisocyanate," Journal of Applied Polymer Science, vol. 107, no. 6, pp. 3891-3902, 2008.

[26] J. Zhao, A. Zhang, Z. Luo et al., "On-line monitoring the curing behaviors of hydroxyl-terminated polybutadiene/toluene diisocyanate system via ultrasonic wave," Journal of Functional Materials, vol. 9, pp. 1649-1652, 2011.

[27] K. Hailu, G. Guthausen, W. Becker, A. König, A. Bendfeld, and E. Geissler, "In-situ characterization of the cure reaction of HTPB and IPDI by simultaneous NMR and IR measurements," Polymer Testing, vol. 29, no. 4, pp. 513-519, 2010.

[28] D. Nagai, M. Sato, B. Ochiai, and T. Endo, "Synthesis and properties of the polythiourethanes obtained by the cationic ring-opening polymerization of cyclic thiourethanes," Journal of Polymer Science Part A: Polymer Chemistry, vol. 44, no. 16, pp. 4795-4803, 2006.

[29] Y. Xiao, B. Jin, R. Peng et al., "Kinetic and thermodynamic analysis of the hydroxyl-terminated polybutadiene binder system by using microcalorimetry," Thermochimica Acta, vol. 659, pp. 13-18, 2018.

[30] H. Salmi, X. Allonas, and C. Ley, "Polythiourethane networks catalyzed by photobase generators," Progress in Organic Coatings, vol. 100, pp. 81-85, 2016.

[31] Y. Guo, D. Tang, and F. Yang, "Transparent fluorinate acrylic polyurethane with hydrophobicity obtained by crosslinking of hydroxyl-containing fluoroacrylate copolymer with HDI trimer," Materials Science-Poland, vol. 33, no. 3, pp. 451-459, 2015.

[32] N. B. H. Mohamed, M. Haouari, N. Jaballah et al., "Optical and IR study of CdS nanoparticles dispersed in a new confined p-phenylenevinylene," Physica B: Condensed Matter, vol. 407, no. 18, pp. 3849-3855, 2012.

[33] K. M. Pradip and K. B. Anil, "Influence of number of functional groups of hyperbranched polyol on cure kinetics and physical properties of polyurethanes," Journal of Polymer 
Science Part A: Polymer Chemistry, vol. 47, no. 3, pp. 731-745, 2009.

[34] W. Du, L. Tan, Y. Zhang, H. Yang, and H. Chen, "Rheological and kinetic investigation into isothermal curing of a thermoset polythiourethane system," Polymer-Plastics Technology and Materials, pp. 1-9, 2019.

[35] S. Akhlaghi, M. Kalaee, E. Jowdar et al., "Simultaneous study of cure kinetics and rheology of montmorillonite/vinyl ester resin nanocomposites," Polymers for Advanced Technologies, vol. 23, no. 3, pp. 534-544, 2012.

[36] J. Hu, X. F. Li, and G. R. Shan, "Study on catalytic mechanism of isocyanates with-SH and-OH groups," Chemical Reaction Engineeirng and Technology, vol. 24, pp. 423-426, 2008.

[37] J. Shin, H. Matsushima, J. W. Chan, and C. E. Hoyle, "Segmented polythiourethane elastomers through sequential thiol-ene and thiol-isocyanate reactions," Macromolecules, vol. 42, no. 9, pp. 3294-3301, 2009.

[38] C.-S. Chern, "Curing kinetics of polyurethane reactions," Journal of Applied Sciences, vol. 40, no. 1112, pp. 2189-2205, 1990.

[39] S. Keskin and S. O. Zkar, "Kinetics of polyurethane formation between glycidyl azide polymer and a triisocyanate," Journal of Applied Polymer Science, vol. 81, no. 4, pp. 918-923, 2001.

[40] D. Kincal and S. Özkar, "Kinetic study of the reaction between hydroxyl-terminated polybutadiene and isophorone diisocyanate in bulk by quantitative FTIR spectroscopy," Journal of Applied Polymer Science, vol. 66, no. 10, pp. 1979-1983, 1997. 


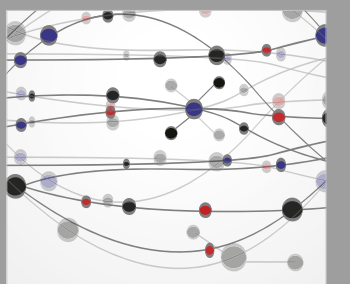

The Scientific World Journal
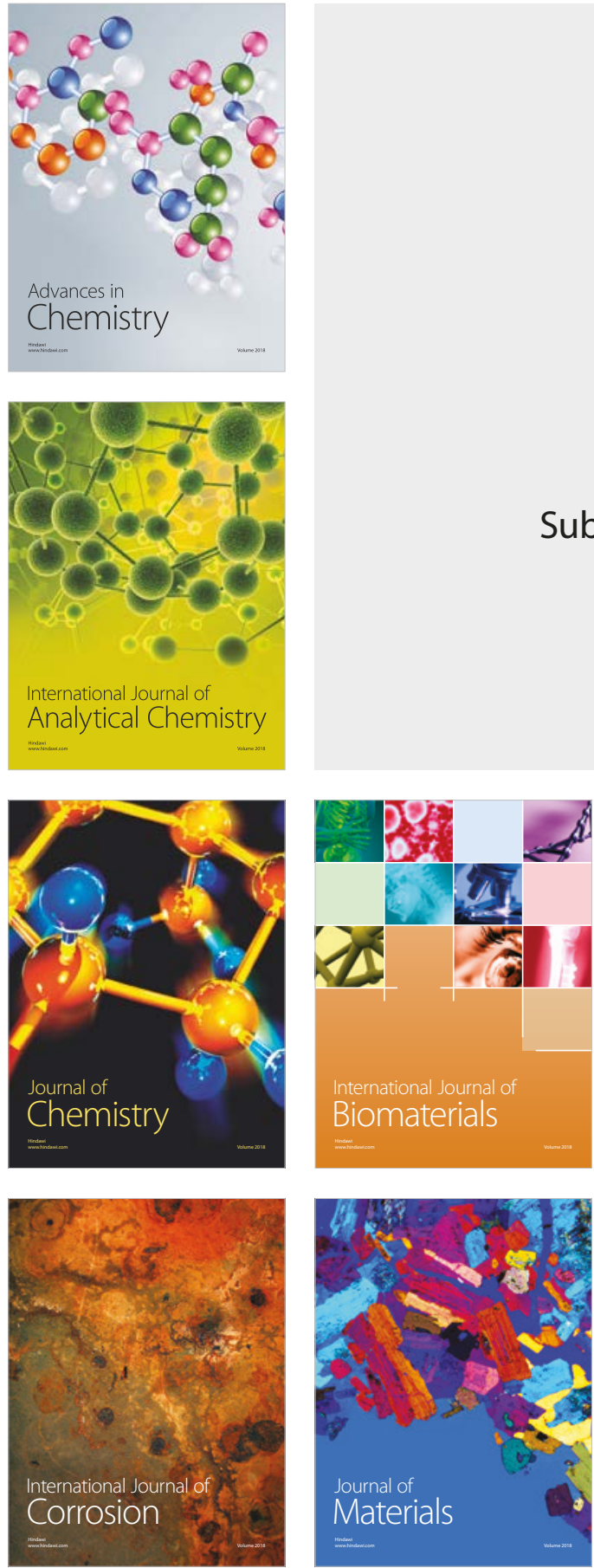

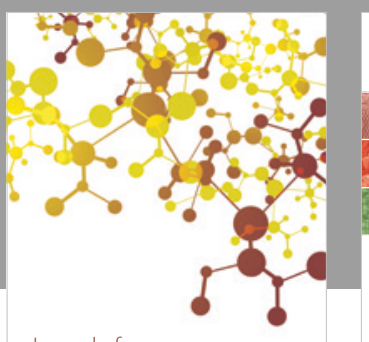

Journal of

Applied Chemistry
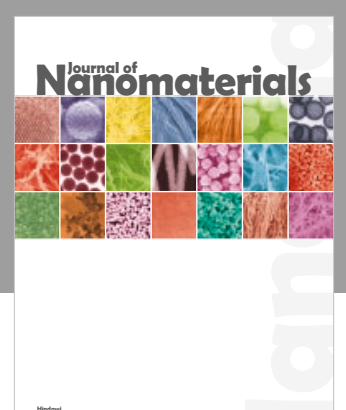

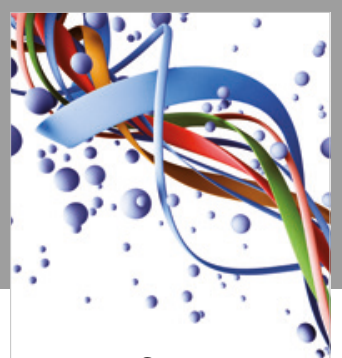

Scientifica

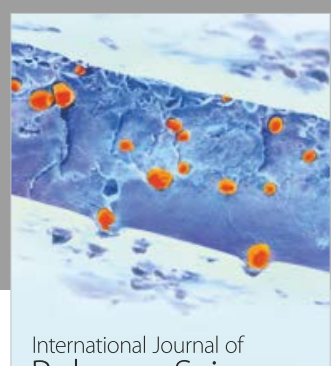

Polymer Science

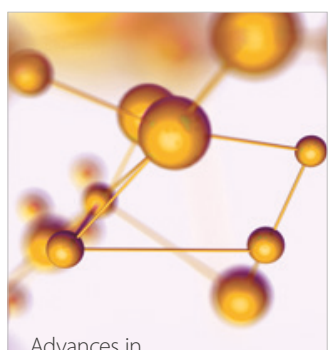

Physical Chemistry
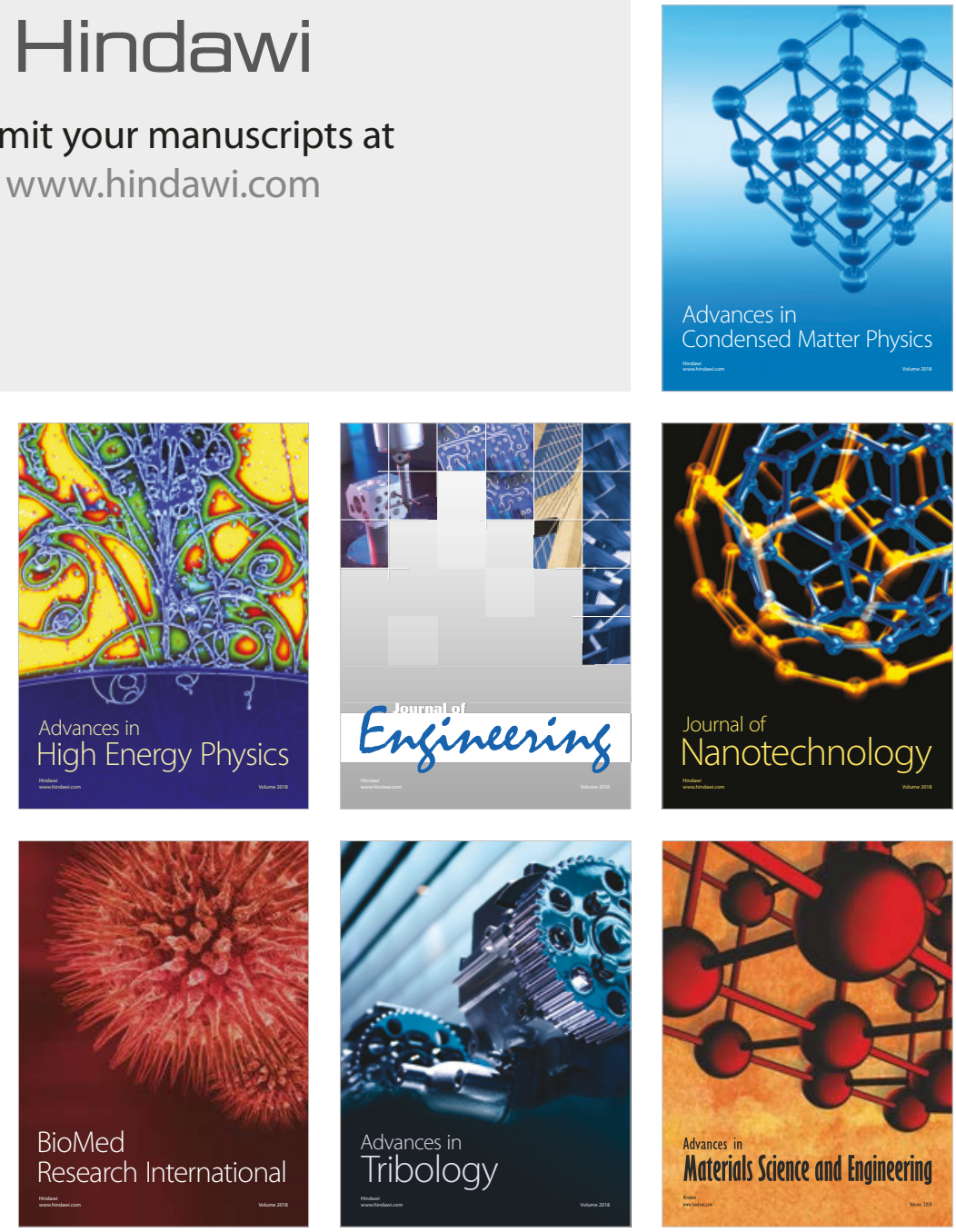